\title{
Evaluating the Impact Of Foreign Exchange Rate Risk On The Capital Budgeting For Multinational Firms
}

Carl B. McGowan, Jr., Norfolk State University, USA

\begin{abstract}
Capital budgeting analysis has evolved to the point where large firms universally use sophisticated capital budgeting techniques. ${ }^{l}$ However, small firms are less likely to use sophisticated capital budgeting techniques. ${ }^{2}$ Even large firms do not generally use simulation for risk analysis in multinational project capital budgeting analysis. ${ }^{3}$ This paper provides a discussion and example of the use of simulation in evaluating the impact of foreign exchange rate volatility on multinational project capital budgeting analysis.
\end{abstract}

Keywords: capital budgeting, foreign exchange risk, and simulation

\section{INTRODUCTION}

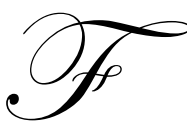

arragher, Kleiman, and Sahu (2001) discuss eight stages in the capital budgeting process. The first three stages encompass finding appropriate projects for consideration: strategic analysis, establishment of corporate goals, and searching for investment opportunities. The next three stages involve the analysis of the project under consideration: forecasting cash flows, evaluating the projected cash flows, and making the decisions to accept or to reject the project. The final two steps are implementing the decision and post-auditing operating performance. In this paper, we deal primarily with the middle three stages of the mechanics of project evaluation and selection.

FKS report that $55 \%$ of respondents perform quantitative risk analysis. Of this number, $95 \%$ use sensitivity analysis and $79 \%$ use scenario analysis. However, only ten percent use simulation analysis. Graham and Harvey (2001) report that $14 \%$ of respondents use simulation analysis. The use of simulation for risk analysis has not increased significantly over the past 30 years. Klammer (1972) reports that $13 \%$ of respondents use simulation, Klammer, Boch, and Wilner (1991) report that $12 \%$ of respondent use simulation, and Ho and Pike (1991) report that $11 \%$ of respondents use simulation. Thus, the proportion of firms using simulation as a part of the capital budgeting process has stayed level at just over ten percent while the use of sophisticated capital budgeting evaluation techniques has increased substantially.

\footnotetext{
${ }^{1}$ Bierman, Harold, Jr. "Capital Budgeting in 1991: A Survey," Financial Management, Autumn 1993, pp. 21-29.

2 See, for example, Block, Stanley. "Integrating Traditional Capital Budgeting Concepts into an International Decision-Making Environment," The Engineering Economist, 45(4), 2000, pp. 309-325 or Graham, John R. and Campbell R. Harvey. "The Theory and Practice of Corporate Finance: Evidence from the Field," Journal of Financial Economics, 60, 2001, pp. 187-243.

${ }^{3}$ See, for example, Farragher, Edward, Robert Kleiman, and Anandi, Sahu. "The Association Between the Use of Sophisticated Capital Budgeting Practices and Corporate Performance," The Engineering Economist, 46(4), 2001, pp. 300-31, Ho, Simon S. M. and Richard H. Pike. "Risk Analysis in Capital Budgeting Contexts: Simple or Sophisticated?," Accounting and Business Research, 21(83), 1991, pp. 227-238, Klammer, T. "Empirical Evidence of the Adoption of Sophisticated Capital Budgeting Techniques," The Journal of Business, July 1972, pp. 387-397, and Klammer, T., B. Koch, and N. Wilner. "Post-auditing Capital Assets and Firm Performance: An Empirical Investigation," Managerial and Decisions Economics, (12), 1991, pp. 317-327.
} 
The first step in making a capital budgeting decision is to forecast future cash flows. The second step is to evaluate the projected cash flows. The third step is to make the decision to accept or to reject the project. Projects with positive net present value (NPV) are accepted and projects with negative NPV are rejected. Alternatively, projects with an internal rate of return (IRR) that is greater than the cost of capital are accepted and projects with an IRR less that the cost of capital are rejected.

The first stage in the capital budgeting project risk analysis process is to estimate the future cash flows of the project. Each variable that affects the future cash flows is estimated with a probability distribution. Probability distributions can range from a simple high, low, best guess estimate to complex distributions of various natures. ${ }^{4}$ Each probability distribution is chosen to best reflect the decision maker's prediction of the nature of the underlying variable process.

Once all of the probability distributions are estimated for the input variables, the simulation is run. A simulation is implemented by selecting a value for each variable and combining all of the values to compute an NPV/IRR for the project. Two options are available for the random selection process, Monte Carlo selection and Latin hypercube selection. Monte Carlo selection selects each value from the full probability distribution. Latin hypercube uses stratified sampling, which restricts the number of observations from each part of the probability distribution. This process is repeated as many times as practicable given the speed of the computer and the time available. In fact, current technology allows for simulation of 100,000 simulations easily. The result is probability distribution of outcomes - NPV/IRR.

This probability distribution of possible outcomes allows the decision maker to get a broad view of what might happen to the capital budgeting project under consideration. The decision maker has the option to do sensitivity analysis to determine which variables affect the outcome the most. That is, which variables affect the decision to accept or to reject the project the most.

\section{DOODAD COMPANY: A CAPITAL BUDGETING EXAMPLE}

Doodad Company currently exports doodads to a low income country. To take advantage of incentives provided by the host country government, and to avoid future political risk, Doodad has decided to begin manufacturing in the host country (LIC). This project will be treated as a stand alone, new venture analysis.

The cost of building and equipping the manufacturing plant in LIC is $\$ 1,000,000$ and will be depreciated over the five year life of the project. Doodad uses straight line depreciation. Doodad believes that the risk level of this project requires a $12.5 \%$ required rate of return. Sales volume in the first year (2000) will be 100,000 units and demand will rise by $10 \%$ each year. The initial price of a unit will be $12 \mathrm{FC}$ and will rise by $15 \%$ each year. Variable cost per unit will begin at $6 \mathrm{FC}$ and rise by $7.5 \%$ per year.

Doodad will repatriate all earnings after taxes as dividends which are subject to a $10 \%$ withholding tax. In addition, Doodad will repatriate the depreciation. To simplify the exposition, US taxes are assumed to be the same as the tax credit for taxes paid in LIC, so no US tax is due.

We construct a table of cash flows for the project and compute the net present value and internal rate of return for Doodad. Table 1 provides the solution to the capital budgeting example for Scenario One. For scenario one, all of the input variables are assumed to be deterministic, that is, know with certainty. The first three rows show the value of the three input variables: sales volume, sales price, variable cost per unit and the expected future spot rate. The level of unit sales volume begins at 100,000 units in year 2000 and grows by ten percent each year to end at 146410 units. The beginning selling price is $\$ 12$ and grows by $15 \%$ each year to end at $\$ 20.99$ per unit. Variable cost per unit begins at $\$ 6$ and grows at 7.5 percent each year to end at $\$ 8.00$ per unit. The fourth variable is the expected future spot rate which begins at 2.00 foreign currency per dollar, is 2.15 foreign currency per dollar, at

\footnotetext{
${ }^{4}$ In this paper, we use the simulation analysis package @RISK published by Palisades Corporation which includes over thirty different probability distributions.
} 
the end of 2000, and grows by 7.5 percent each year to end at 2.87 foreign currency per dollar. The IRR for this scenario is 18.9 percent and the NPV for this scenario is $\$ 182,704$.

Table 2 provides a solution to the same capital budgeting example but with Sales volume starting at 120,000 units. $^{5}$ With increased sales volume, the IRR increases to $25.14 \%$ and the NPV increases to $\$ 375,881$. The financial decision maker can change variable inputs to determine the sensitivity of IRR to changes in each input variable. Scenario analysis allows the decision maker to determine which input variable has the most significant impact of IRR. The capital budgeting project can be restructured to mitigate the effect of those input variables where only a small adverse change in the input variable changes the IRR decision.

A significant scenario level for each input variable is the level at which the IRR is equal to the required rate of return, $12.5 \%$. The NPV is zero at this point. For sales volume, the zero NPV level is 81,804 units. For sales price, this level is $\$ 10.72$ per unit. For unit variable cost, this level is $\$ 7.47$ pre unit. For the foreign exchange rate variable, the break-even, starting level is $\$ 2.54$. The break-even level for the cost of the project is $\$ 1,182,704$.

Figures 1-4 show the probability distributions assumed for each of the input variables. ${ }^{6}$ Sale volume is assumed to be a triangular distribution with a minimum value of 95,000 units and a maximum value of 105,000 units. Sales price is assumed to be a histogram distribution with values between $\$ 11$ and $\$ 13$. The bottom and top one-third each have a probability of $20 \%$ and the middle one-third has a probability of $60 \%$. The growth rate of the expected future foreign exchange rate is assumed to normally be distributed with a growth rate of $7.5 \%$ per with a standard deviation of $1 \%$. The exchange rate at time zero is assumed to be 2.00 foreign currency per dollar.

Figures 5-8 show the actual probability distributions for the input variables used in the simulation. Figures 9-10 show the actual probability distributions for the IRR and the NPV used in the simulation. Table 3 shows the statistics generated by the simulation.

Unit volume has a mean of 100,000 units with a maximum of 104,991 units and a minimum of 95,018 units. Unit selling price has a mean of 12, a minimum of 11 and a maximum of 13. Unit cost has a mean value of 7 with a minimum of 5 and a maximum of 7 . The foreign exchange rate has a mean of 2.15 foreign currency per dollar with a minimum of 2.06 foreign currency per dollar and a maximum of 2.24 foreign currency per dollar.

The NPV for the project is $\$ 182,811$ with a maximum of $\$ 514,545$ and a minimum of $-\$ 122,330$. The IRR has a mean of $18.84 \%$ with a minimum of 7.93 percent and a maximum of 29.57 . The probability of a positive NPV is greater than $95 \%$.

At this point, the decision maker can determine the critical variables which have the greatest impact of the decision to accept or to reject the project. Managerial time, which is a limited resource, can be used where the time will have the most impact, those variables whose volatilities have the most influence on the outcome. It is an easy matter for the decision maker to develop various scenarios for the input variables or the probability distributions for the input variables. This type of sensitivity analysis allows the decision maker to evaluate the impact of each input variable on the possible outcome.

\section{AUTHOR INFORMATION}

Carl B. McGowan, Jr., PhD, CFA is a Professor of Finance at the School of Business at Norfolk State University. Dr. McGowan received a BA in International Relations and an ROTC commission from Syracuse University, an MBA (Finance) from Eastern Michigan University, and a PhD in Business Administration (Finance) from Michigan State University. From 2003 to 2004, he was the RHB Bank Distinguished Chair in Finance at the Universiti

\footnotetext{
${ }^{5}$ Scenario analysis is single iteration simulation. One variable is changed and the outcome is recomputed. The impact of each variable can be determined for significant points such as the zero NPV point.

${ }^{6}$ The probability distributions are chosen to show the variety of distributions available. @ RISK provides thirty different probability distributions.
} 
Kebangsaan Malaysia. He has taught in Cost Rica, Malaysia, Moscow, Saudi Arabia, and The UAE. His special area of interest is international risk analysis and foreign direct investment analysis analyzing the interaction between political and economic risk and FDI. Professor McGowan has published over one hundred papers and presented over one hundred and forty papers at conferences. Professor McGowan published in numerous journals including Applied Financial Economics, Decision Science, Financial Practice and Education, The Financial Review, The Journal of Applied Business Research, The Journal of Diversity Management, The Journal of Global Business, The Journal of Real Estate Research, Managerial Finance, The Southwestern Economic Review, and Urban Studies.

\section{BIBLIOGRAPHY}

1. Bierman, Harold, Jr. “Capital Budgeting in 1991: A Survey,” Financial Management, Autumn 1993, pp. 21-29.

2. Block, Stanley. "Integrating Traditional Capital Budgeting Concepts into an International Decision-Making Environment," The Engineering Economist, 45(4), 2000, pp. 309-325.

3. Farragher, Edward, Robert Kleiman, and Anandi, Sahu. "The Association Between the Use of Sophisticated Capital Budgeting Practices and Corporate Performance," The Engineering Economist, 46(4), 2001, pp. 300-311.

4. Graham, John R. and Campbell R. Harvey. "The Theory and Practice of Corporate Finance: Evidence from the Field," Journal of Financial Economics, 60, 2001, pp. 187-243.

5. Ho, Simon S. M. and Richard H. Pike. "Risk Analysis in Capital Budgeting Contexts: Simple or Sophisticated?," Accounting and Business Research, 21(83), 1991, pp. 227-238.

6. Klammer, T. "Empirical Evidence of the Adoption of Sophisticated Capital Budgeting Techniques," The Journal of Business, July 1972, pp. 387-397.

7. Klammer, T., B. Koch, and N. Wilner. "Post-auditing Capital Assets and Firm Performance: An Empirical Investigation," Managerial and Decisions Economics, (12), 1991, pp. 317-327.

8. $\quad$ Pike, Richard H. "An Empirical Study of the Adoption of Sophisticated Capital Budgeting Practices and Decision-Making Effectiveness,” Accounting and Business Research, 18(72), 1988, pp. 341-351.

9. Reichert, Alan K., James S. Moore, and Ezra Byler. "Financial Analysis among Large US Corporations: Recent Trends and the Impact of the Personal Computer," Journal of Business, Finance, and Accounting, 15(4), Winter 1988, pp. 469-485. 
Figure 1

Probability Distribution - Sales Volume

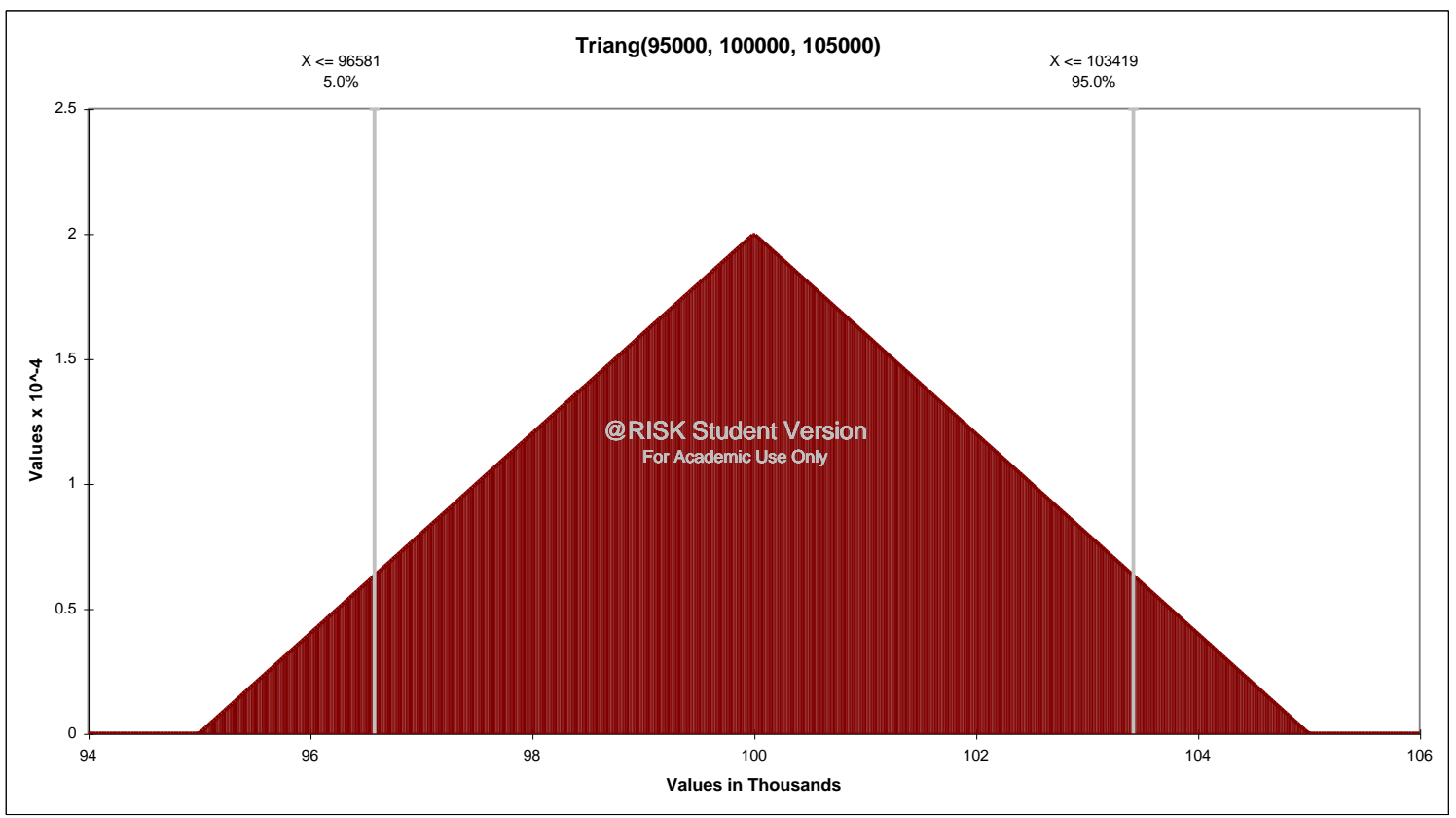

Figure 2

Probability Distribution - Selling Price

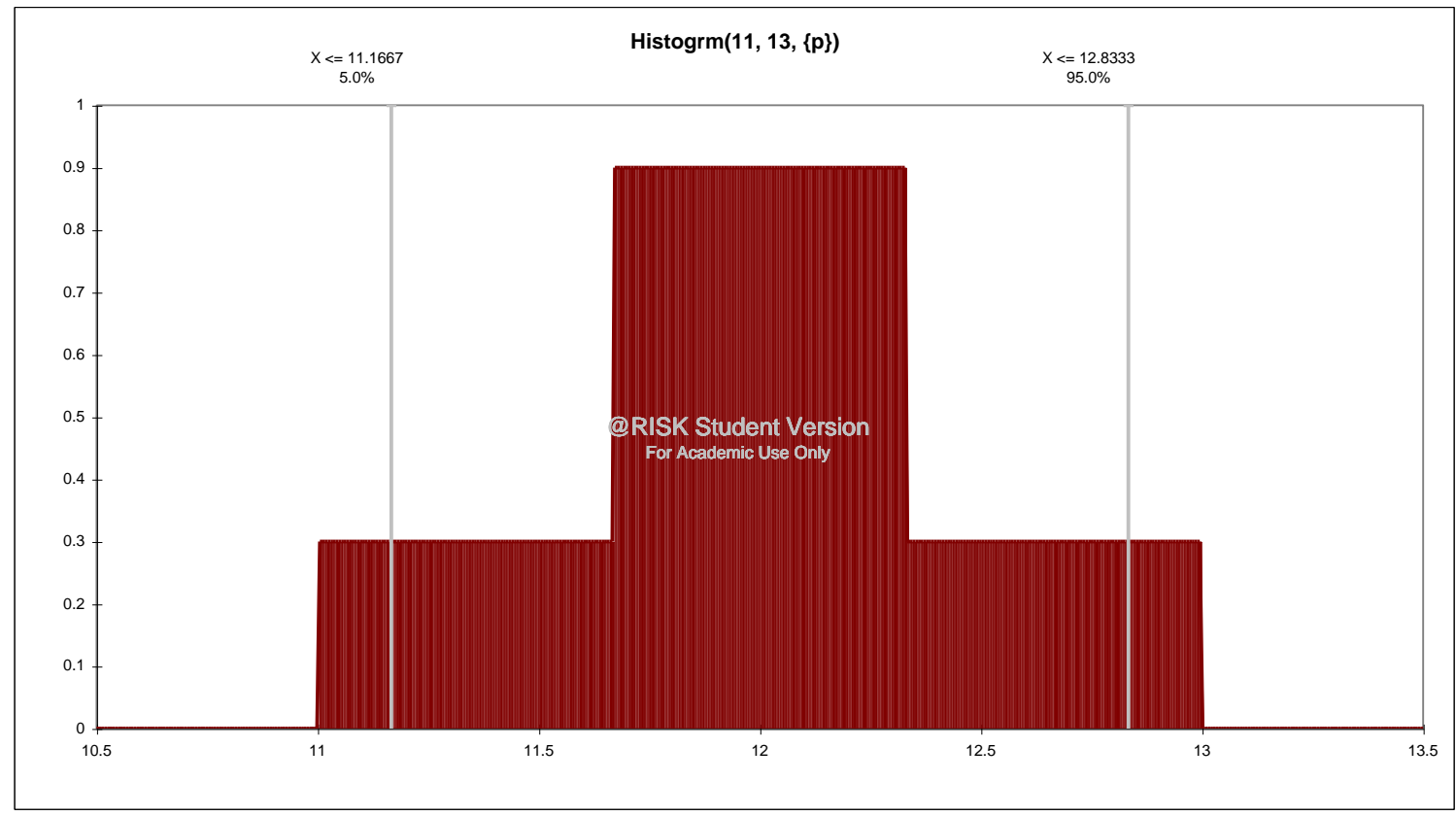


Figure 3

Probability Distribution - Unit Cost

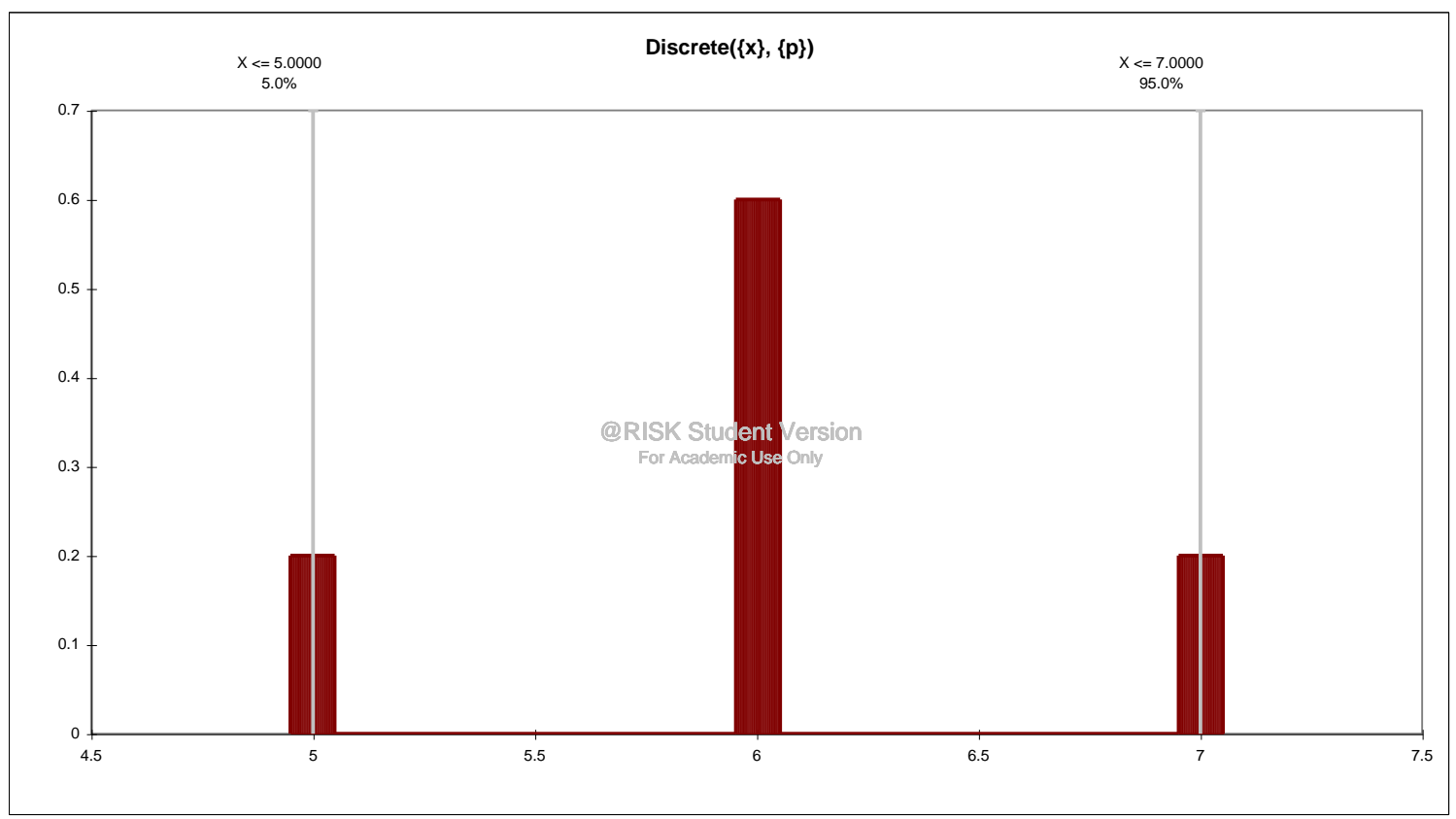

Figure 4

Probability Distribution - Foreign Exchange Rate Change

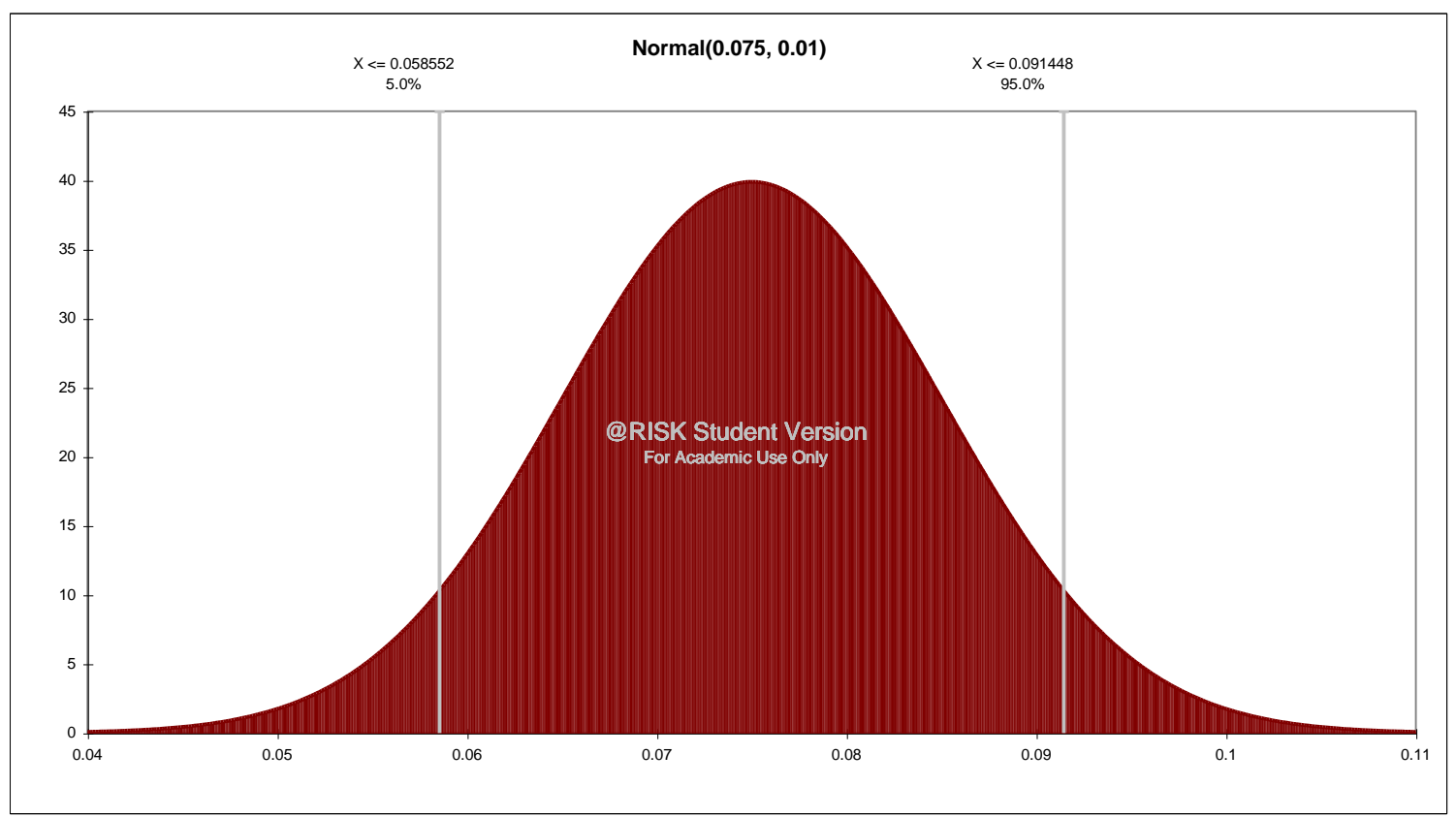


Figure 5

Output Distribution - Unit Volume

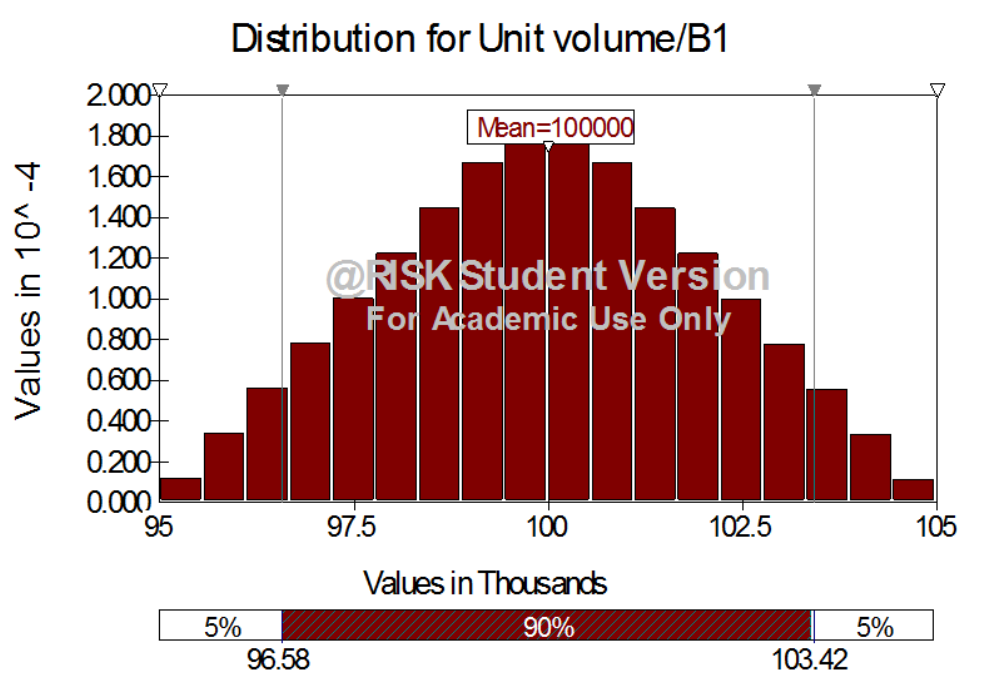

Figure 6

Output Distribution - Selling Price

Distribution for Unit sales/B2

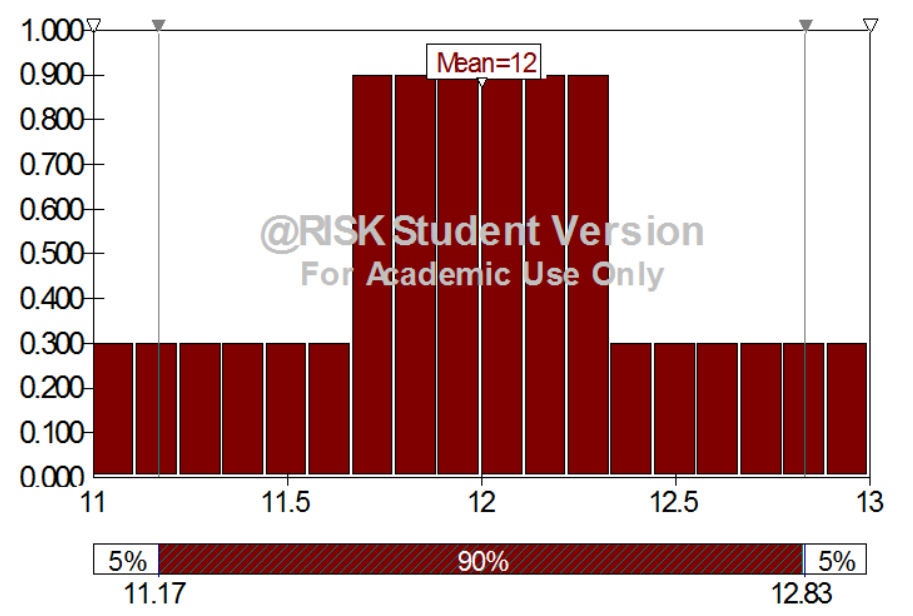


Figure 7

Output Distribution - Unit Cost

Distribution for Unit cost/B3

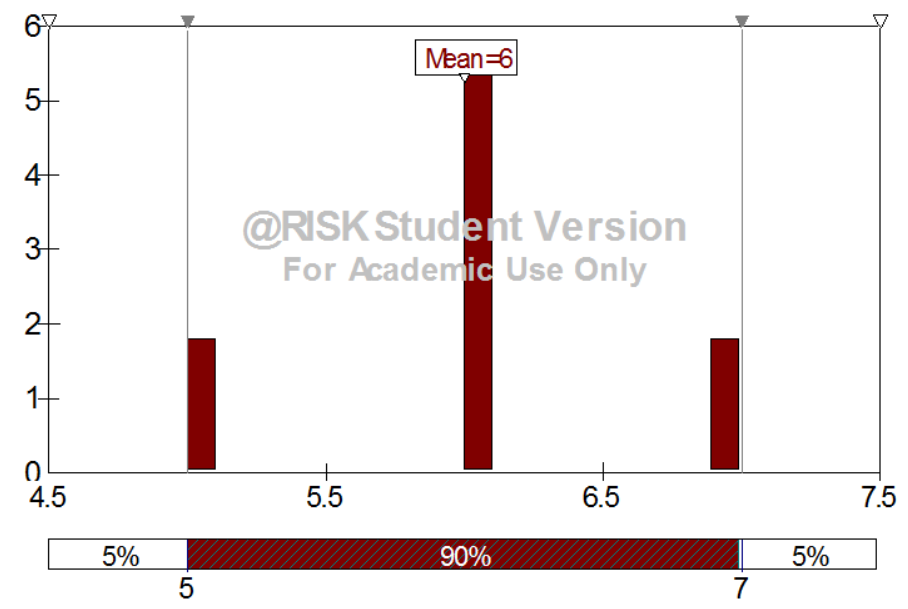

Figure 8

Output Distribution - Foreign Exchange Rate

Distribution for FX rate/B4

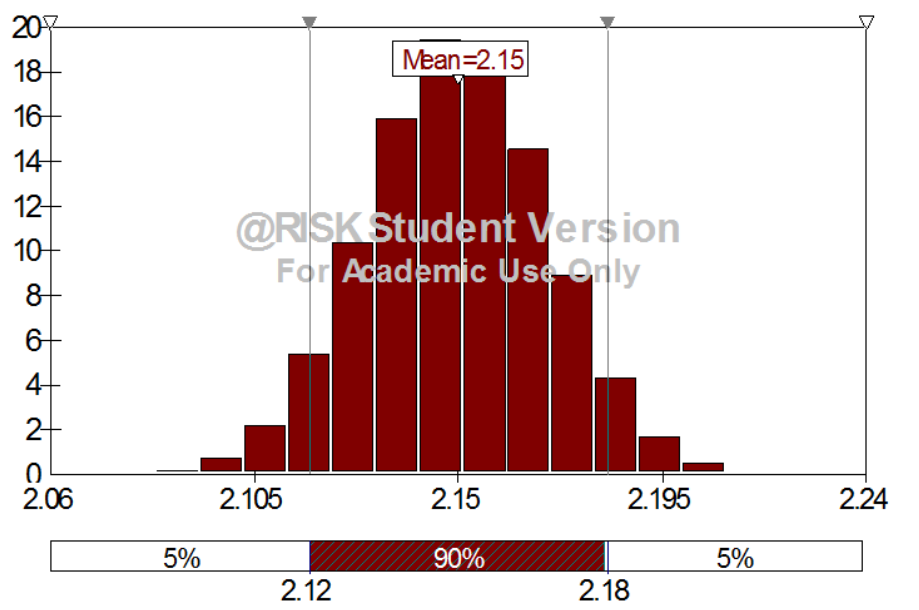


Figure 9

Output Distribution - Net Present Value

Distribution for NPV / 2000/C34

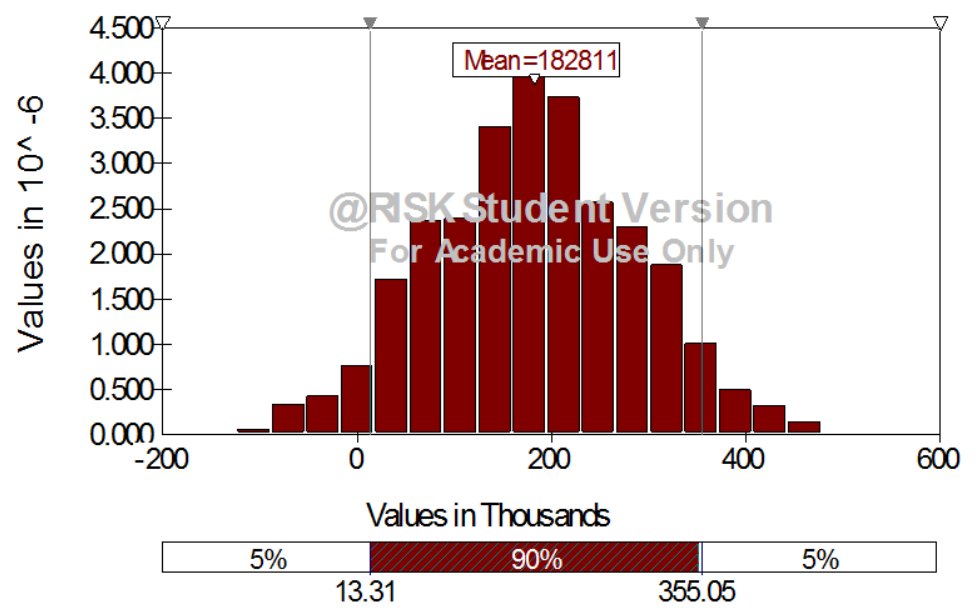

Figure 10

Output Distribution - Internal Rate of Return

Distribution for IRR / 2000/C36

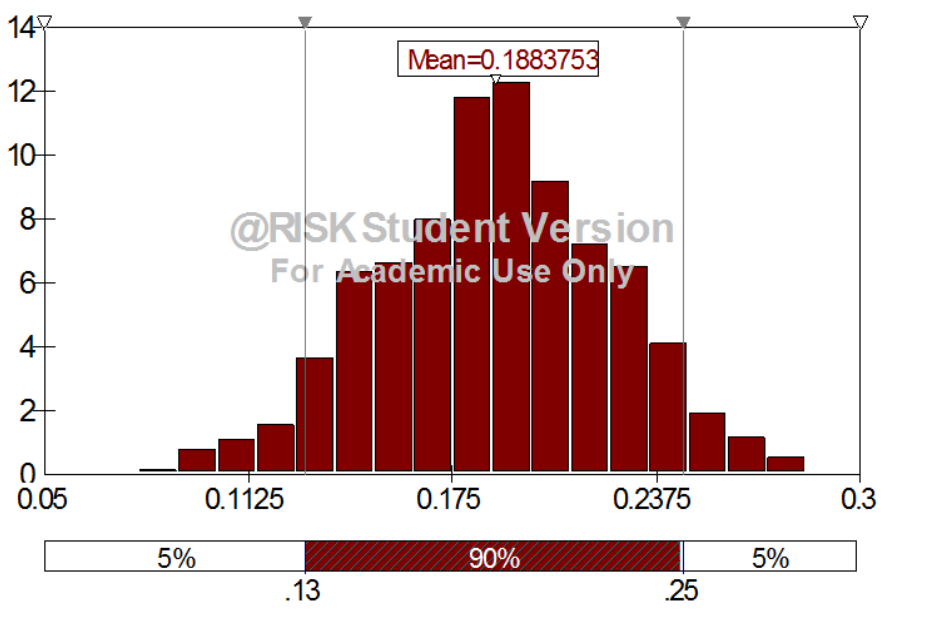




\begin{tabular}{|c|c|c|c|c|c|c|}
\hline \multicolumn{7}{|c|}{$\begin{array}{c}\text { Table 1 } \\
\text { NPV Computation } \\
\text { Scenario One }\end{array}$} \\
\hline Year & & 2008 & 2009 & 2010 & 2011 & 2012 \\
\hline Volume & & 100000 & 110000 & 121000 & 133100 & 146410 \\
\hline Price & & 12.00 & 13.80 & 15.87 & 18.25 & 20.99 \\
\hline Variable cost per unit & & 6.00 & 6.45 & 6.93 & 7.45 & 8.01 \\
\hline Revenue & & 1200000 & 1518000 & 1920270 & 2429142 & 3072864 \\
\hline Variable costs & & 600000 & 709500 & 838984 & 992098 & 1173156 \\
\hline Depreciation & & 400000 & 400000 & 400000 & 400000 & 400000 \\
\hline EBT & & 200000 & 408500 & 681286 & 1037043 & 1499708 \\
\hline Taxes $(30 \%)$ & & 60000 & 122550 & 204386 & 311113 & 449912 \\
\hline EAT & & 140000 & 285950 & 476900 & 725930 & 1049795 \\
\hline Dividend payment & & 140000 & 285950 & 476900 & 725930 & 1049795 \\
\hline Taxes & & 14000 & 28595 & 47690 & 72593 & 104980 \\
\hline Net & & 126000 & 257355 & 429210 & 653337 & 944816 \\
\hline FOREX rate & & 2.15 & 2.31 & 2.48 & 2.67 & 2.87 \\
\hline Depreciation (\$) & & 186047 & 173067 & 160992 & 149760 & 139312 \\
\hline Dividend (\$) & & 58605 & 111349 & 172749 & 244610 & 329060 \\
\hline Total $(\$)$ & -1000000 & 244651 & 284415 & 333741 & 394370 & 468372 \\
\hline $\mathrm{PV}(\$)$ & & 1182704 & & & & \\
\hline Cost $(\$)$ & & 1000000 & & & & \\
\hline NPV & & 182704 & & & & \\
\hline IRR & & $18.90 \%$ & & & & \\
\hline
\end{tabular}




\begin{tabular}{|c|c|c|c|c|c|c|}
\hline \multicolumn{7}{|c|}{$\begin{array}{c}\text { Table 2 } \\
\text { NPV Computation } \\
\text { Scenario One } \\
\end{array}$} \\
\hline Year & & 2008 & 2009 & 2010 & 2011 & 2012 \\
\hline Volume & & 120000 & 132000 & 145200 & 159720 & 175692 \\
\hline Price & & 12.00 & 13.80 & 15.87 & 18.25 & 20.99 \\
\hline Variable cost per unit & & 6.00 & 6.45 & 6.93 & 7.45 & 8.01 \\
\hline Revenue & & 1440000 & 1821600 & 2304324 & 2914970 & 3687437 \\
\hline Variable costs & & 720000 & 851400 & 1006781 & 1190518 & 1407787 \\
\hline Depreciation & & 400000 & 400000 & 400000 & 400000 & 400000 \\
\hline EBT & & 320000 & 570200 & 897544 & 1324452 & 1879649 \\
\hline Taxes $(30 \%)$ & & 96000 & 171060 & 269263 & 397336 & 563895 \\
\hline EAT & & 224000 & 399140 & 628280 & 927116 & 1315755 \\
\hline Dividend payment & & 224000 & 399140 & 628280 & 927116 & 1315755 \\
\hline Taxes & & 22400 & 39914 & 62828 & 92712 & 131575 \\
\hline Net & & 201600 & 359226 & 565452 & 834405 & 1184179 \\
\hline FOREX rate & & 2.15 & 2.31 & 2.48 & 2.67 & 2.87 \\
\hline Depreciation (\$) & & 186047 & 173067 & 160992 & 149760 & 139312 \\
\hline Dividend (\$) & & 93767 & 155425 & 227583 & 312401 & 412425 \\
\hline Total $(\$)$ & -1000000 & 279814 & 328492 & 388576 & 462161 & 551737 \\
\hline $\mathrm{PV}(\$)$ & & 1375881 & & & & \\
\hline Cost $(\$)$ & & 1000000 & & & & \\
\hline NPV & & 375881 & & & & \\
\hline IRR & & $25.14 \%$ & & & & \\
\hline
\end{tabular}




\section{Table 3 Output Statistics}

\begin{tabular}{|c|c|c|c|c|c|c|}
\hline Outputs & Volume & Price & Cost & FX rate & NPV / 2000 & IRR / 2000 \\
\hline Minimum & 95018 & 11.00 & 5.00 & 2.06 & -122330 & 0.0793 \\
\hline Maximum & 104991 & 13.00 & 7.00 & 2.24 & 514545 & 0.2957 \\
\hline Mean & 100000 & 12.00 & 6.00 & 2.15 & 182811 & 0.1884 \\
\hline Standard Deviation & 2041 & 0.46 & 0.63 & 0.02 & 105266 & 0.0358 \\
\hline Variance & 4166707 & 0.21 & 0.40 & 0.00 & $1.11 \mathrm{E}+10$ & 0.00 \\
\hline Skewness & 0.00 & 0.00 & 0.00 & 0.00 & 0.02 & -0.07 \\
\hline Kurtosis & 2.40 & 2.62 & 2.50 & 3.00 & 2.79 & 2.81 \\
\hline Number of Errors & 0 & 0 & 0 & 0 & 0 & 0 \\
\hline Mode & 96030 & 11.29 & 6 & 2.10 & -39537 & 0.1847 \\
\hline $5 \%$ & 96581 & 11.17 & 5 & 2.12 & 13327 & 0.1298 \\
\hline $10 \%$ & 97236 & 11.33 & 5 & 2.12 & 46295 & 0.1416 \\
\hline $15 \%$ & 97739 & 11.50 & 5 & 2.13 & 68073 & 0.1493 \\
\hline $20 \%$ & 98162 & 11.67 & 6 & 2.13 & 89273 & 0.1568 \\
\hline $25 \%$ & 98535 & 11.72 & 6 & 2.14 & 110876 & 0.1643 \\
\hline $30 \%$ & 98873 & 11.78 & 6 & 2.14 & 130148 & 0.1710 \\
\hline $35 \%$ & 99183 & 11.83 & 6 & 2.14 & 146014 & 0.1765 \\
\hline $40 \%$ & 99472 & 11.89 & 6 & 2.14 & 158994 & 0.1809 \\
\hline $45 \%$ & 99743 & 11.94 & 6 & 2.15 & 171012 & 0.1850 \\
\hline $50 \%$ & 100000 & 12.00 & 6 & 2.15 & 182432 & 0.1889 \\
\hline $55 \%$ & 100257 & 12.06 & 6 & 2.15 & 194259 & 0.1929 \\
\hline $60 \%$ & 100528 & 12.11 & 6 & 2.16 & 206160 & 0.1969 \\
\hline $65 \%$ & 100817 & 12.17 & 6 & 2.16 & 219424 & 0.2013 \\
\hline $70 \%$ & 101127 & 12.22 & 6 & 2.16 & 235059 & 0.2065 \\
\hline $75 \%$ & 101464 & 12.28 & 6 & 2.16 & 253990 & 0.2128 \\
\hline $80 \%$ & 101838 & 12.33 & 7 & 2.17 & 275030 & 0.2198 \\
\hline $85 \%$ & 102261 & 12.50 & 7 & 2.17 & 296645 & 0.2269 \\
\hline $90 \%$ & 102764 & 12.67 & 7 & 2.18 & 320516 & 0.2346 \\
\hline $95 \%$ & 103419 & 12.83 & 7 & 2.18 & 355048 & 0.2459 \\
\hline
\end{tabular}

